\title{
An Experience Report Assessing A Professional Development MOOC For CS Principles
}

\author{
Jeff Gray \\ University of Alabama \\ Tuscaloosa, AL, USA \\ gray@cs.ua.edu
}

\author{
Jonathan Corley \\ University of Alabama \\ Tuscaloosa, AL, USA \\ corle001@crimson.ua.edu
}

\author{
Brian P. Eddy \\ University of West Florida \\ Pensacola, FL, USA \\ beddy@uwf.edu
}

\begin{abstract}
CS Principles is a new AP course being developed by the College Board and introduced into high schools across the nation. To aid and encourage the adoption of the new CSP course, we have developed a Massively-Open Online Course (MOOC) over the past two years that serves as a professional development (PD) offering for CS Principles. Additionally, we have provided a parallel face-to-face workshop for a smaller group of MOOC participants. In this paper, we discuss our experiences conducting PD using a MOOC. We investigated the impact of the face-to-face event and online community on participants' completion and performance in the course. Our analysis suggests that participants who have even just a few days of face-to-face engagement tend to be more successful in completing a multi-week MOOC.
\end{abstract}

\section{Keywords}

MOOC; Professional Development; Hybrid Learning Env.

\section{INTRODUCTION}

CS Principles (CSP) is a new AP CS course being introduced into high schools across the nation, with the first exam targeted for May 2017 [1. To aid and encourage the adoption of AP CSP, we offered a Massively-Open Online Course (MOOC) providing a gentle introduction to the CSP Curriculum Framework (CF) and Performance Tasks (PTs) 2]. The MOOC evolved from a non-majors course at the University of Alabama (with special focus on Secondary Math Education majors and $67 \%$ enrollment by women) that was a College Board pilot course. The university-focused course served as the basis for an NSF-supported project (NSF CE21: NSF\#1240944) that offers year-long CSP training to high school teachers across the state of Alabama. The MOOC curriculum is driven by a combination of the university course and shared resources developed by the teachers in the NSF project 9]. The content delivery needs led to an online version of the course that evolved into a free MOOC coupled with a one week local face-to-face meeting,

Permission to make digital or hard copies of all or part of this work for personal or classroom use is granted without fee provided that copies are not made or distributed for profit or commercial advantage and that copies bear this notice and the full citation on the first page. Copyrights for components of this work owned by others than ACM must be honored. Abstracting with credit is permitted. To copy otherwise, or republish, to post on servers or to redistribute to lists, requires prior specific permission and/or a fee. Request permissions from permissions@ acm.org.

SIGCSE '16 March 2-5, 2016, Memphis, TN, USA

(C) 2015 ACM. ISBN 123-4567-24-567/08/06 .. \$15.00

DOI: http://dx.doi.org/10.1145/2839509.2844654 the CS4Alabama PD workshop, held for the teachers in the NSF project. The MOOC, CSP4HS 2], has been supported by Google for two offerings of the course in 2014 and 2015. The most recent offering enrolled over 1,065 educators from 48 states (sans Wyoming and Vermont) in the USA and 39 other countries. Six other states used our MOOC for their CSP content mixed with their own local 3-5 day face-to-face meetings. This paper reports on the Alabama experiences.

The current version of the MOOC is teacher-facing and designed for professional development (PD) of teachers who have little background in computer science. However, we offer a variety of resources that we strive to update for each new offering. Thus, we also provide some content of value to past participants. The current offering of the course includes six units of instruction spanning topics of the Big Ideas of CSP utilizing the following key components.

1. Course Materials ${ }^{1}$ provided to participants include:
a) training modules for the CSP CF and PTs
b) over 120 video $2^{2}$ for teachers and students
c) lesson plans developed by teacher leaders
d) lesson slides
e) quizzes and exams
f) a pacing guide and syllabus

2. Piazza-based community of practice for teachers participating in the course

3. Course-wide broadcast through Google Hangouts on Air for synchronous interaction with MOOC instructors as well as invited guests

4. Virtual Face-To-Face through Google Hangouts

A certificate is available for those participants who complete all quizzes and exams, along with a solo version of the Create PT. Although focused on summer participation, the MOOC resources are available year-round.

The driving philosophy behind both the NSF project and MOOC is the idea of "for teachers, by teachers." Many of the MOOC resources have been created and vetted by teachers from our NSF project. The MOOC co-instructors are also high school teachers who have been teaching CSP for several years. This philosophy has contributed to what we feel is the major success of this MOOC, a vibrant and active

\footnotetext{
${ }^{1}$ http://tinyurl.com/CSP4HS-2015-Resources

${ }^{2}$ http://tinyurl.com/CS4Alabama-YouTube
} 


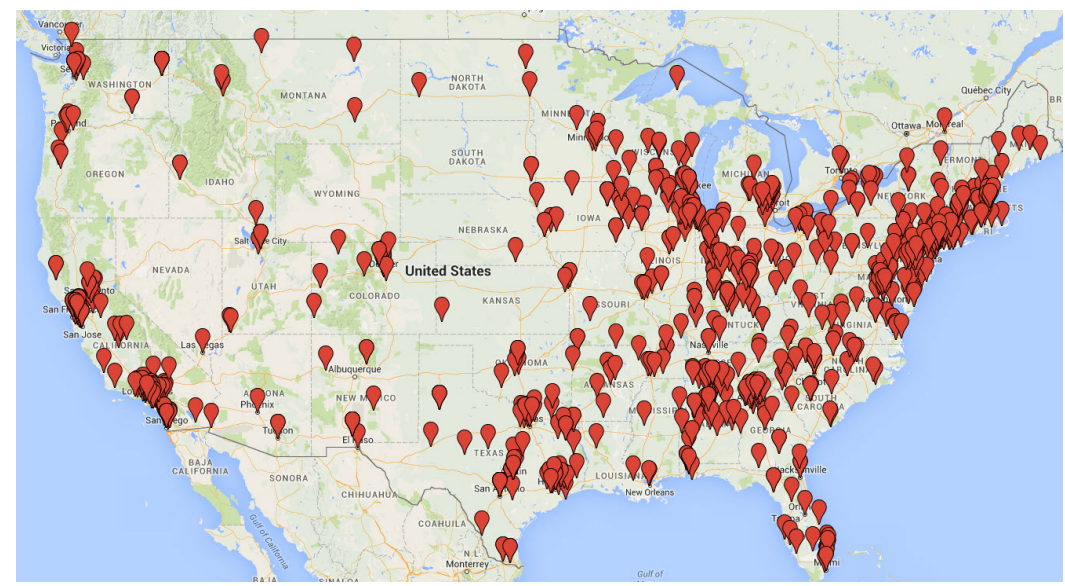

Figure 1: CSP4HS Participants in Continental USA

community of practice driven by the needs, concerns, and suggestions of classroom teachers.

In this paper, we present an experience report describing our activities, challenges, and lessons learned offering a MOOC for teacher PD. We begin in Section 2 by introducing the key components of the MOOC along with some demographic information describing the participant diversity. Section 3 discusses the primary challenges encountered in development of the MOOC, including the following:

1. coordinating rapid, large scale communication from course participants

2. creating and adapting curriculum content in the presence of evolving changes from the College Board development process

3. managing the grading and communicating the results of assessment instruments

4. significantly underestimating the initial time needed to develop course materials for an online presence

5. intgrating a cocktail of tools that were used to deliver the course

6. understanding how to address differentiated needs among many participants with varied backgrounds and abilities

Additionally, whereas prior work in the area has explored the concerns of face-to-face PD [8], we investigated the impact of face-to-face meetings and an online community on participants' completion and performance in the course.

\section{OVERVIEW OF CSP4HS}

In this section, we introduce the key components of the MOOC and the face-to-face workshop, and we present demographic data regarding enrollment in the course and the face-to-face event.

\subsection{CSP CS4HS 2015: A CSP PD MOOC}

The MOOC had four primary components: the course materials, Piazza (an online forum designed for integration into the classroom), Hangouts on Air (Google Hangouts broadcast to YouTube), and virtual face-to-face (small group Google Hangouts facilitated by our instructors).

\subsubsection{Course Materials}

The primary course materials consisted of a Google Course Builder course 2], a set of quizzes and exams built using Google Forms, and a set of Lesson Videos hosted on YouTube. Google Course Builder [4] was used to craft a set of six units each consisting of several lessons. A complete lesson contained the lesson videos (embedded in the page), links to a variety of relevant sources including the slides from the lesson video, links to freely available resources, relevant videos from our face-to-face event, and a textual guide discussing all the content that ties together the overall lesson with sample activities and discussion questions. Very frequently, we would also direct participants in the course to post on Piazza regarding certain aspects of the lessons. These discussions sparked conversation between participants and enabled us to directly converse with course participants regarding the content of the lessons.

A common component of all course lessons was links to external sources relevant to the lesson topic. This was a key feature of the course designed to expose participants to the vast wealth of other CSP resources available online. Because preparing educators to teach CSP concepts was a primary goal of the course, we included links to videos and activities covering key lesson concepts (e.g., YouTube videos, Code.org activities, or CS Unplugged activities). We also directed participants to lesson plans and teaching resources relevant to course topics from a variety of sources 3

\subsubsection{Asynchronous Community Discussion Forum}

The course used Piazza 6] as an open forum for discussion among all participants involved in the course (participants and instructors). The instructors could post announcements, run polls, post questions, answer questions, and endorse answers and posts made by participants. Most threads were public and available to all participants, but we also allowed private threads between a single participant and the instructors, or within a specific subgroup (e.g., the six other states that used our MOOC for content, but provided their own face-to-face meetings each had their own subgroup). We maintained dedicated threads for each les-

\footnotetext{
${ }^{3}$ These sources include but are not limited to http:// apcsprinciples.org/, https://cs10kcommunity.org/, https:// apcommunity.collegeboard.org/
} 
son, each HOA (discussed in Section 2.1.3), and other central concepts. These dedicated threads helped maintain discussion of a specific topic within a single location, but many other topics were discussed and numerous private threads were posted. There were over 3,800 posts to the Piazza community, with an average response time of 33 minutes for replies to posted questions.

\subsubsection{Live Guest Talks}

Hangouts on Air (HoA) is a Google Hangout 5] that simulcasts (with slight delay) and archives to a YouTube channel. The HOAs provided an opportunity for the entire class to listen to a broadcast from a guest speaker(s) who is very influential in the CSP community, and to ask questions via a dedicated Piazza thread. Several HOAs have also been incorporated into the lessons as a video resource (i.e., embedded YouTube video of a previously recorded HOA broadcast).

\subsubsection{Synchronized Group Office Hours}

We used traditional Google Hangouts [5] to serve as virtual office hours (i.e., face-to-face meetings) among a small group of participants (10 or less) facilitated by one of our instructors; i.e., High School teachers with several years experience teaching CSP (two are national College Board Pilot instructors) recruited to assist with the course. The Hangouts focused on discussing current topics related to the course, and were offered nearly daily during the initial six weeks of the course. The Hangouts were filled in a firstcome, first-served basis and scheduled through a dedicated Piazza thread for each Hangout.

\subsection{Face-to-Face Meetings}

We held a face-to-face PD workshop designed to prepare 47 teachers from across Alabama to teach CSP, as part of our multi-year PD model. This workshop is part of an NSF grant (NSF CE21) that funds activities to train teachers along with developing curriculum for the AP CSP course.

The workshop reinforced several concepts introduced in the MOOC, including programming using Snap!, recruitment strategies, as well as deep discussions and group activities surrounding the CSP PTs. The workshop lasted one week running from $9 \mathrm{am}$ to $4 \mathrm{pm}$ most days with 2 evening activities. We had returning participants from previous workshops as well as new participants. We often offered parallel sessions to allow our returning participants to cover more advanced or expanded topics. Our MOOC was also used by six other states who were funded by Google CS4HS. The online content of our MOOC was supplemented by face-to-face meetings within each state.

\subsection{Course Demographics}

As a freely available online course, we attracted a large and widely diverse group of participants. To capture the widely varying demographics for the course, we took an initial survey of all those interested in the course. With over 1,065 participants completing this survey of interest, we immediately observed several interesting trends.

\subsubsection{Intent to Complete the Course}

Our MOOC attracted a number of participants only interested in browsing the course materials, including some who had taken a previous iteration of the course in 2014. Nearly

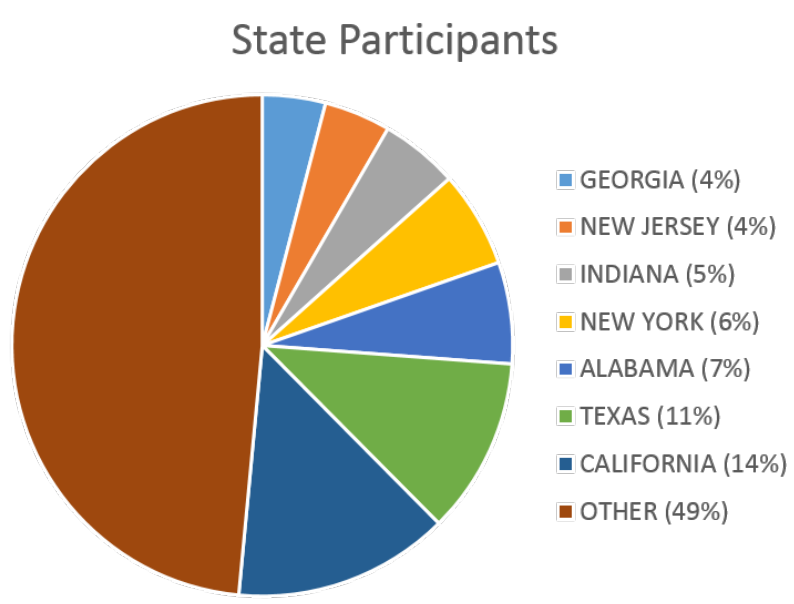

Figure 2: Participants per State

$5 \%$ of our participants indicated an interest in browsing the materials, but not in completing the course requirements to earn the various PD certificates. Even more notable, over $30 \%$ of respondents indicated they intended to partially complete the course, but would not strive to earn any of the PD certificates. Some of these two groups indicated they had previously completed the course and were browsing for new material and updates. Others still indicated they were passively interested in the course materials and intended only to seek a general understanding of the concepts covered by the course. Most interesting to us is that $65 \%$ of the participants indicated that they wished to pursue the complete course, including earning the certificate. However, only about $13 \%$ completed the majority of certificate requirements. A focus of this paper is to understand why participant followthrough has been so low, as common to other MOOCs.

\subsubsection{Gender Diversity}

We also teach a CSP course for non-majors at the university level, which has been a national College Board Pilot since 2011. The Fall 2015 course enrollment has $67 \%$ women. There is a similar gender tilt toward women in our MOOC, with the participants at $57 \%$ women.

\subsubsection{Geographically Dispersed}

Our original hope was to draw participants from across our state and even some participants from across the nation into our online community. To our surprise and delight, these expectations have been met and well surpassed. The enrollment for the 2015 offering of this course included 48 states and over 39 countries. Fig. 1 displays the geographic spread across the continental US, and Fig. 2 illustrates the states with the largest enrollment in the course.

\subsubsection{Teaching Focus}

The course was offered primarily as PD in support of the new AP CSP course. As such, our primary audience was high school educators. To gain a better understanding of the diversity of educators, we asked several questions regarding where, how, and what our respondents teach. Fig. 3a illustrates the type of school at which our participants teach. The vast majority teach at public schools 


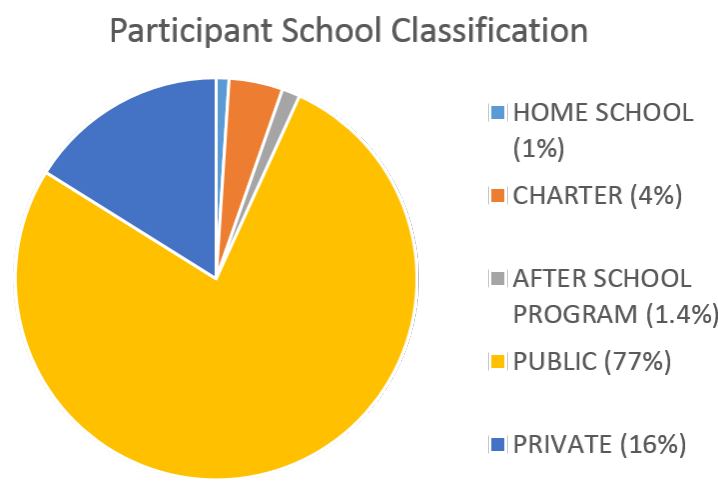

(a) Classification of Schools

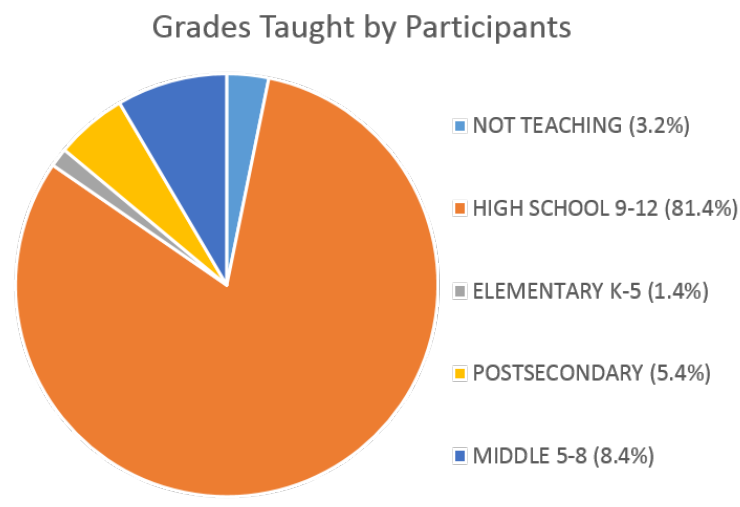

(b) Grades Taught

Figure 3: Teaching Demographics of MOOC Participants

Percent of Participants Teaching Subject Areas

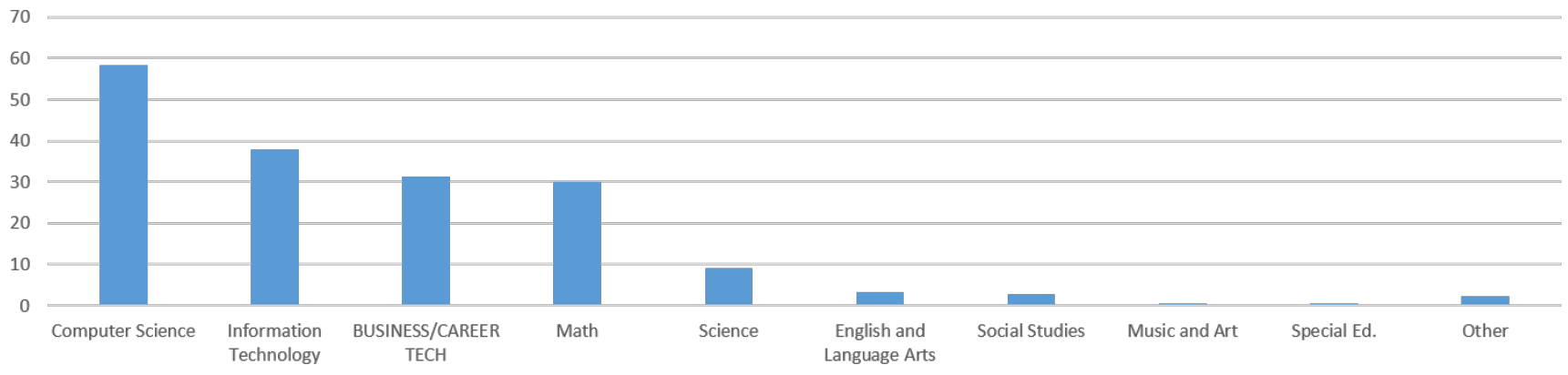

Figure 4: Subject Areas Taught by Participants

$(77 \%)$ with the next largest group being private schools $(16 \%)$. However, there were also participants from charter schools (4\%), homeschool programs (1\%), and even after school programs $(1.4 \%)$. When queried about which grades they taught (Fig. 3b), the vast majority taught High School $(81.4 \%)$ as expected for the AP course material, but we also had participants who teach Elementary (1.4\%), Middle $(8.4 \%)$, and Post-secondary (5.4\%). Finally, Fig. 4 displays the percentage of participants who teach at least one course in a specific subject area.

We were also interested in whether the participants currently or planned to teach CSP. We found that $15 \%$ currently teach CSP, and $45 \%$ plan to teach CSP in the future. Only $3 \%$ indicated they would not consider teaching the course, with the remaining $37 \%$ open to the possibility of teaching CSP at some point in the future.

\subsubsection{Prior Knowledge}

A key concern of managing the course and materials was understanding the experience of the participants. Therefore, we asked a set of questions to gather information regarding our participants CS education, CS teaching experience, and knowledge of programming languages and environments. We found that approximately $46 \%$ of participants had taken one or two courses covering CS topics; $16 \%$ had taken 3-4 courses; and a surprisingly sizeable $38 \%$ had taken 5 or more courses covering CS.
Regarding CS teaching experience, $43 \%$ indicated little or no experience teaching CS courses. Of the remainder, $25 \%$ had notable experience teaching CS and $27 \%$ indicated they had experience teaching CSP. We believe the expressed interest in the course is driven by recent changes to the Curriculum Framework by the College Board and the addition of new resources (e.g., lesson plans) being advertised as available through the MOOC that are specifically designed to aid teachers who plan to explore CSP.

We also identified the programming languages known or used by the participants, and were surprised at the variety of languages listed. In total, participants listed 121 languages. The top languages and environments included Scratch (used by $51 \%)$, Java (51\%), C++ (35\%), Javascript (32\%), Python (31\%), Alice (29\%), and App Inventor (27\%). Nearly $10 \%$ of participants had no experience with any programming language or environment.

\section{LESSONS LEARNED}

This section summarizes some of the challenges that we faced in offering the MOOC, as well as an assessment that we made on the impact of face-to-face and online communities toward course completion and content mastery.

\subsection{Challenges Encountered During the MOOC}

Our MOOC is in its second version, which has allowed us to reflect back on some of the experiences during its devel- 
opment. The main challenges we faced are summarized in the following subsections.

\subsubsection{Creating and Developing Course Materials and Curriculum}

As with most reports of online course development 7], the amount of time needed to curate and design the set of curricular resources is significantly greater compared to teaching a face-to-face course. A particular challenge has been the changes to the CSP Curriculum Framework during the College Board's pilot development, which forced us to revisit and recreate videos and resources from the previous year's offering.

\subsubsection{Managing Communication at Scale}

Even though our MOOC was a much more modest offering than more large-scale courses (we had barely more than 1,000 participants in 2015), we still experienced the shock of scale during the initial communication with course participants. Before the Piazza community began to settle in its role, we received over 850 emails on the first day of the course opening. Coordinating the community responses and replies from the course instructors required considerable planning.

\subsubsection{Managing Grading at Scale}

Several online courses have used automated tools, as well as peer grading, to handle the challenges of assessing student performance in a course. We had approximately 3,065 quizzes that were graded automatically using Flubaroo 3 (a Google Docs plugin for managing forms-based quizzes), which provided a summary of all quiz responses for analysis and also communicated results to the participants. To achieve consistency in grading the Create PT homework, we developed a rubric and a subset of our course instructors graded the homework submissions, rather than using peer grading.

\subsubsection{Differentiated Learners at Scale}

In the same way that a traditional classroom has students with mixed abilities requiring the practice of differentiated learning strategies, the issue is even more evident in a MOOC. With participants who have a very deep background, to those who have never programmed before, we needed to create special opportunities to challenge those with more experience while offering additional instruction for those who are newly initiated to CS.

\subsubsection{Integrating Disparate Tools to Create a Cohe- sive Course Environment}

We used a cocktail of tools to support the online experience, including: Google Course Builder for hosting the main course site, Piazza for forming the community of practice discussion area, Google Docs and Flubaroo for surveys and assessments, Google Drive for course resources, YouTube for video resources, and both Hangouts and Hangouts on Air for synchronous communication. These tools often did not integrate with each other natively (e.g., Course Builder and Flubaroo), and the number of different tools needed to participate and follow along in the course was confusing to some participants. A more integrated MOOC experience would likely reduce any stress associated with completing the course.

\subsection{Impact of Face-to-Face}

The face-to-face portion of the course included the PD workshop for our Alabama teachers. The purpose of the face-to-face portion of the course was to provide teachers who were planning to teach CSP in the future with a more interactive learning environment where they could work more closely with the instructors of the course than was possible through online instruction alone. Our goal was to help teachers develop the confidence they needed to succeed in teaching the course, as well as help them to build and establish a community of practice among peers.

We evaluated whether the teachers who participated in our own statewide face-to-face session went on to complete the course and if they were more successful in completing the material than those who did not participate in the faceto-face workshop. To this aim, we analyzed the results of the course in terms of the percentage of the course and scores on course assessments for teachers who completed the face-toface versus participants who did not. For our comparisons, we looked at only those teachers who had full interest in completing the course as judged by the pre-course surveys.

\subsubsection{Impact of Face-to-Face on Course Completion}

We first looked at whether there was a difference between the completion rates of the teachers who participated in the face-to-face event and those who did not. We judged this based off of the percentage of lessons completed, the completion of the course midterm, and the completion of the course's Create PT homework. We found that on average, the teachers who completed the face-to-face event completed $88 \%$ of the course, while the teachers who did not complete the face-to-face event only completed $21 \%$ of the course on average. We performed a Wilcoxon rank-sum test between the two groups, which is the non-parametric analogue of the t-test, and found a significant difference $(p<0.05)$ between the two groups. We consider this observation to be a major finding and contribution of this paper toward better understanding the importance of face-to-face workshops on completion of hybrid PD courses.

\subsubsection{Impact of Face-to-Face on Course Assessments}

Second, we looked at the results of the course midterm and the course's Create PT. On average, the teachers who participated in the face-to-face event scored an $89 \%$ on the course midterm on average and $80 \%$ on the Create PT on average. Teachers who did not participate in the face-to-face scored a $92 \%$ on the course midterm on average and a $78 \%$ on the Create PT on average. While the midterm percentage is slightly higher for the group that did not participate in the face-to-face, a statistically significant difference was not found between the groups. Furthermore, the percentage of the teachers who completed the face-to-face who also completed the midterm was $88 \%$, whereas the percentage was only $13 \%$ for those teachers who did not. We believe that the face-to-face session gave teachers, who typically would not have completed the midterm or homework, the confidence to do so.

\subsubsection{Impact of Face-to-Face on Participation in On- line Discussion}

Finally, we were interested in whether the teachers who completed the face-to-face event were more likely to participate in the online discussion. We looked at both the 
percentage of the teachers who participated in some form of online discussion and the number of contributions each participant in this group made to the online discussions. We found that on average, the teachers who participated in the face-to-face event made 9 contributions to the online discussion and $88 \%$ of the teachers participated in some form of online discussion. For the teachers who did not participate in the face-to-face event, we found that they made on average 6 contributions to the online discussion and only $35 \%$ participated in the online discussion. For those teachers who participated in the online community, we did not find a significant difference in the number of contributions between those that participated in the face-to-face event and those who did not.

\subsection{Impact of Online Community}

The online community allowed teachers to communicate asynchronously with their peers and instructors to ask questions, discuss the course material, and to learn about additional material related to CS and to teaching CS in the classroom. In addition, it was included as a way for teachers to build a network of their peers that they may not have been able to otherwise. Teachers could participate in the online community regardless of whether they participated in the face-to-face or not.

We evaluated whether the teachers who participated in the online community were more successful at completing the material than those who did not. Like the analysis of the face-to-face event, we analyzed the results of the course in terms of the percentage of the course and scores on course assessments for teachers who participated in the online community versus teachers who did not. Again, we looked at only those teachers who had full interest in completing the course as judged by the pre-course surveys.

\subsubsection{Impact of Online Community on Course Com- pletion}

Similar to the face-to-face workshop, we first looked at whether there was a difference between the completion rates of the teachers who participated in the online community and those who did not. We found that on average, the teachers who participated in the online community completed $35 \%$ of the course, while the teachers who did not participate in the online community only completed $15 \%$ of the course on average. We found a significant difference ( $p$ $<0.05)$ between the two groups.

\subsubsection{Impact of Online Community on Course As- sessments}

We then looked at the results of the course midterm and the course's Create PT. On average, the teachers who participated in the online community scored a $93 \%$ on the course midterm on average and $84 \%$ on the Create PT on average. Teachers who did not participate in the online community scored $92 \%$ on the course midterm on average and a $78 \%$ on the Create PT on average. For both the course midterm and for the Create PT, the averages were higher for teachers who participated in the online community. While no significant difference was found between the course midterms, a difference was found between the Create PT averages of the two groups. Furthermore, the percentage who participated in the online community who also completed the midterm was $22 \%$ and the Create PT was $17 \%$, whereas the percent- age was only $8 \%$ for midterms and $6 \%$ for the Create PT for those who did not participate in the online community.

\section{CONCLUSIONS AND FUTURE WORK}

Over the course of two offerings of a MOOC for PD on CSP, we have encountered a number of challenge that range from managing simple concerns (e.g., participant communication) to more complex issues (e.g., addressing differentiated course needs among a large group of participants with varying backgrounds and abilities). In this paper, we discussed our experiences with these challenges and the lessons learned. Furthermore, we investigated the impact of our face-to-face event and online community with respect to participants' completion and performance in the course.

As future work, we hope to investigate further the impact of the various key course components through additional data collection and analysis. Our goal is to understand the benefits of providing online and face-to-face interactions among participants and how these interactions impact success in the course. Additionally, we hope to be able to gather information regarding use of MOOC materials in classrooms and as reference resources for past participants.

\section{ACKNOWLEDGMENTS}

This work is supported by NSF CE21 (CNS 1240944) and Google CS4HS.

We would like to thank the following who assisted with the instruction and development of the MOOC: Jeff Baker, Roy Black, Lydia Eubanks, Rachael Giles, Gina McCarley, Deepa Muralidhar, Michele Roberts, Lauri Springer, Jake Trower, Jill Westerlund.

\section{REFERENCES}

[1] AP CS Principles. http://apcsprinciples.org/. Accessed: 08-29-2015.

[2] CSP4HS. https://csp-cs4hs.appspot.com/preview.

[3] Flubaroo. http://www.flubaroo.com/. Accessed: 08-29-2015.

[4] Google Course Builder. https://www.google.com/edu/openonline/index.html. Accessed: 08-29-2015.

[5] Google Hangouts. https://plus.google.com/hangouts Accessed: 08-29-2015.

[6] Piazza. https://piazza.com/ Accessed: 08-29-2015.

[7] J. Burge. Insights into teaching and learning: Reflections on mooc experiences. In Proceedings of the 46th ACM Technical Symposium on Computer Science Education, SIGCSE '15, pages 600-603, Kansas City, MO, 2015.

[8] S. Cooper, S. H. Rodger, M. Schep, R. H. Stalvey, and W. Dann. Growing a k-12 community of practice. In Proceedings of the 46th ACM Technical Symposium on Computer Science Education, SIGCSE '15, pages 290-295, Kansas City, MO, 2015.

[9] J. Gray, K. Haynie, S. Packman, M. Boehm, C. Crawford, and D. Muralidhar. A mid-project report on a statewide professional development model for cs principles. In Proceedings of the 46th ACM Technical Symposium on Computer Science Education, SIGCSE '15, pages 380-385, Kansas City, MO, 2015. 